\title{
Fixing Sensor Position Using Computational Fluid Dynamic Analysis for Trace Detection of Toxic Gases
}

\author{
M. V. Shyla ${ }^{1 *}$, K. B. Naidu' and G. Vasanth Kumar ${ }^{2}$ \\ 'Department of Mathematics, Sathyabama University, Chennai-600119, India; \\ shylamv@yahoo.com, kbnaidu999@gmail.com \\ ${ }^{2}$ Department of Aeronautical Engineering, Sathyabama University, Chennai-600119, India; \\ vassa.aero@gmail.com
}

\begin{abstract}
High exposures of hydrogen-cyanide following accidental releases are very toxic. Hence this paper focuses on trace detection of accidental release of hydrogen-cyanide in industries. Computational Fluid dynamic (CFD) simulation of hydrogen-cyanide around circular sensors that is fixed at different locations under steady state condition with laminar and turbulent boundary conditions is performed for trace detection of accidental release of hydrogen-cyanide in industries. The CFD model is generated using Gambit software. CFD analysis is done using Fluent software which employs CFD technique, finite volume method to compute velocity profile, pressure distribution, and streamline pattern. This study provides sufficient details of dynamic flow of hydrogen cyanide which is achieved by designing sensors using CFD simulation. Comparing the velocity magnitudes of low velocity region and pressure values in various models, a variation in velocity magnitude and pressure values are observed around the circular sensors in Model 2, Model 3 and Model 4. But the magnitude of velocity and pressure values around the three sensors in Model 1 remains the same. The results reveal the fact that the flow is disturbed by the placement of sensors in all models except Model 1. Hence Model 1 is considered as the best model in this study. The sensor positions in 4 models are compared using the flow pattern of hydrogen cyanide around the circular sensors in various models. It is identified that the flow is undisturbed by the placement of sensors in Model 1. This information can be used in fixing sensors in an optimal position in industries and indoor environment to increase the efficiency of sensing.
\end{abstract}

Keywords: Computational Fluid Dynamic Analysis, Finite Volume Method, Fixing Sensor Position, Laminar, Steady Flow, Turbulent

\section{Introduction}

Low levels of hydrogen-cyanide are found in all parts of the environment and do not cause any significant environmental damage. High exposures following accidental releases are highly toxic. It obstructs the transport of oxygen around the body. Hydrogen-cyanide gas in air at concentration over $5.6 \%$ is an explosive. It is listed among the chemical warfare agents. ${ }^{1}$. It was used during the World War II in the German concentration camp mass killing. Researchers have developed different models of hydrogen cyanide detection sensors. Model 4101-22 gas detector utilizes electrochemical technology to detect levels of Hydrogen Cyanide in the range 0 to $20 \mathrm{ppm}^{2}$. TA2102 HCN Gas detectors can detect 0-50 PPM HCN $\mathrm{Gas}^{3}$. Single-Gas Detector, $\mathrm{HCN}$ can detect 0 to $30 \mathrm{ppm}^{4}$. These detectors are not able to give sufficient details of dynamic flow of hydrogen cyanide. This problem can be overcome by designing sensors using CFD simulation.

Computational fluid dynamic simulations are much effective and cheaper when compared to the experimental study. A modified multizone model ${ }^{5}$, is used to analyze the suitable placement of chemical and biological toxic sensors in a building. The contaminant flow

*Author for correspondence 
time in a zone is not considered since the model assumed instantaneous mixing in each zone. The multizone model is not able to give clear and complete information about the sensor position. To obtain more accurate and detailed results researchers ${ }^{6-14}$ prefer CFD modeling. Researchers have also developed different search strategies to localize the source of the leak?

CFD analysis of spherical gas sensor array ${ }^{8}$, is studied in a two dimensional flow field with laminar main flow. But optimal sensor position is not analyzed. Later the optimal sensor positions for chemical and biological agent releases in buildings are studied ${ }^{9}$. Their study revealed that CFD simulation can be used to find the sensor deployment location. Optimal sensor placement during a chemical and biological contaminant threat in a city is studied $^{10}$, with CFD modeling. The contaminant transport details are pre-computed, stored, and interpreted with a nomograph technique. Their analysis depends on the assumed weather conditions. CFD studies also concentrated on optimal sensor placement for hazardous material transports ${ }^{11}$, around buildings. Identification of contaminant sources in enclosed environments by inverse CFD modeling is done. CFD programs are used ${ }^{12}$, to monitor cabin air quality, infectious disease transmission, and intentional airborne contaminant releases in commercial aircraft cabins. CFD model for indoor plume propagation $^{13}$, is analyzed using Fluent software to predict a two dimensional plane flow field in a building. CFD model is developed for search strategy to localize the source of leak using robots ${ }^{7}$. Optimal sensor position on different surfaces like spherical, cylindrical, cubical, and prism using CFD analysis ${ }^{14}$, is studied for reducing accidents caused by emission of toxic gas in industries.

In this paper, we study two dimensional flow fields with laminar and turbulent flow at low cost to simulate flow of hydrogen-cyanide around circular gas sensors used for indoor plume tracing. CFD simulation is performed by fixing sensors at different positions in different models in an indoor set up and the models are compared. The information on the flow pattern can be used in identifying and fixing the optimal sensor position in an indoor environment and industries relating to hydrogen-cyanide for effective trace detection.

The paper is organized as follows: The governing differential equations and boundary conditions are given in the first part. The second part discusses the methodology. The third part explains the results of this study in detail. The concluding remarks are presented in the last part.

\section{Mathematical Formulation}

\subsection{Governing Differential Equation}

The governing differential equations for a steady, incompressible flow are given by Navier-Stokes system of equations namely the equation of continuity and the momentum equations.

Equation of continuity:

$$
\frac{\partial u}{\partial x}+\frac{\partial v}{\partial y}=0
$$

$\mathrm{x}$-momentum equation:

$$
\rho\left(u \frac{\partial u}{\partial x}+v \frac{\partial u}{\partial y}\right)=-\frac{\partial p}{\partial x}+\mu\left(\frac{\partial^{2} u}{\partial x^{2}}+\frac{\partial^{2} u}{\partial y^{2}}\right)
$$

y-momentum: equation:

$$
\rho\left(u \frac{\partial v}{\partial x}+v \frac{\partial v}{\partial y}\right)=-\frac{\partial p}{\partial y}+\mu\left(\frac{\partial^{2} v}{\partial x^{2}}+\frac{\partial^{2} v}{\partial y^{2}}\right)
$$

$\vec{q}=u \vec{i}+v \vec{j}$ is the velocity vector where $\mathrm{u}$ and $\mathrm{v}$ are the velocity components in the $\mathrm{x} \& \mathrm{y}$ directions respectively, $p$ is pressure, $\rho$ is density, and $\mu$ is coefficient of viscosity.

The entire domain under consideration in physical space with Cartesian coordinates $(\mathrm{x}, \mathrm{y})$ is transformed to computational space with curvilinear coordinates $(\xi, \eta)$ for problems involving complex geometries, and then solved. Once the solution is obtained, it is transferred back to physical space ${ }^{15,16}$.

\subsection{Boundary Conditions}

The circular sensors are placed at different positions in different models in an indoor environment. When air flows, it brings a gas cloud from the inlet which flows along the circular sensor before it is being carried away into the wake. A two dimensional flow of hydrogencyanide is simulated around circular sensors under steady state conditions. The operating pressure is kept at 101325 Pascals. Body forces are all ignored. The inlet velocity of $0.01 \mathrm{~m} / \mathrm{s}$ and $0.5 \mathrm{~m} / \mathrm{s}$ is taken for laminar flow and turbulent flow respectively. The walls are considered to be rigid. No slip boundary condition is assumed. The physical properties of hydrogen-cyanide is taken for analysis with density $\rho=1 \mathrm{~kg} / \mathrm{m} 3$ and coefficient of viscosity $\mu=1.72 \mathrm{e}-05 \mathrm{~kg} / \mathrm{m}-\mathrm{s}$. 


\section{Methodology}

The computational fluid dynamic model geometry is developed using the CFD software, Gambit as presented in Figure 1. The dimensions of the building section are taken as $100 \mathrm{~m}$ and $50 \mathrm{~m}$ in the $\mathrm{x}$ and $\mathrm{y}$ directions respectively with circle radius $1 \mathrm{~m}$. The sensors in 4 models have the following arrangement. Model 1 has 3 sensors centered at $(25,25),(75,10)$, and $(75,40)$.

Model 2 has 4 sensors with centre at $(25,10),(25,40)$, $(75,10)$, and $(75,40)$. Model 3 has 3 sensors positioned with centre at $(25,40),(50,25)$, and $(75,40)$. Model 4 has 3 sensors with centre at $(25,40),(50,25)$, and $(75,10)$.

Computational fluid dynamic technique namely finite volume method is applied and it consists of 3 steps. In the first step, discretization of the entire domain into finite number of control volumes is done. In the next step analysis is performed followed by the post processing of the results.

\subsection{Discretization}

The quadrilateral pave mesh with interval size 0.25 is generated for the entire domain under consideration for all the models. The number of nodes and quadrilateral cells for each model are presented in Table 1. The two dimensional mesh is exported to Fluent software for analysis.

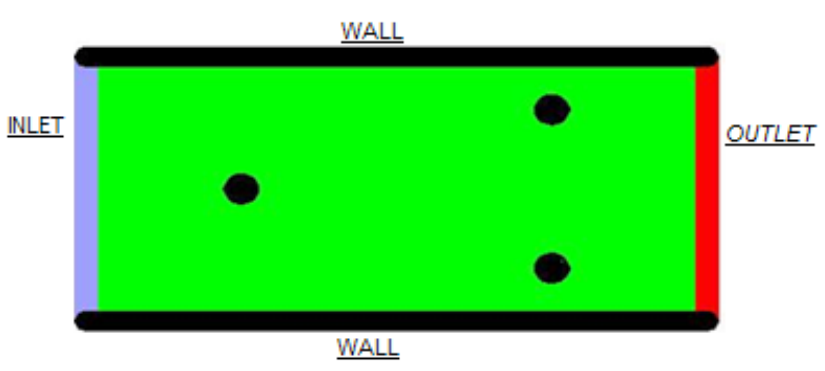

Figure 1. Grid of Model 1.

Table 1. Discretization

\begin{tabular}{lcc}
\hline Model & No. of Nodes & $\begin{array}{c}\text { No. of Quadrilateral } \\
\text { cells }\end{array}$ \\
\hline 1 & 82613 & 81976 \\
2 & 82859 & 82210 \\
3 & 81929 & 81292 \\
4 & 81862 & 81225 \\
\hline
\end{tabular}

The partial differential system of equations is discretized by upwind differencing scheme over each control volume and they are reduced to algebraic system of equations as follows:

$$
\frac{(\rho u A)_{e}-(\rho u A)_{w}}{\Delta x}+\frac{(\rho v A)_{n}-(\rho v A)_{s}}{\Delta y}=0
$$

$$
\begin{gathered}
\frac{(\rho u A)_{e} u_{e}-(\rho u A)_{w} u_{w}}{\Delta x}+\frac{(\rho u A)_{n} v_{n}-(\rho u A)_{s} v_{s}}{\Delta y} \\
=\frac{\left(p_{w}-p_{e}\right)}{\Delta x} \Delta V_{u}+\left\{\left[\frac{\left(\mu \frac{\partial u}{\partial x}\right)_{e}-\left(\mu \frac{\partial u}{\partial x}\right)_{w}}{\Delta x}\right]\right. \\
\left.+\left[\frac{\left(\mu \frac{\partial u}{\partial y}\right)_{n}-\left(\mu \frac{\partial u}{\partial y}\right)_{s}}{\Delta y}\right]\right\} \Delta V_{u}
\end{gathered}
$$

$$
\begin{gathered}
\frac{(\rho v A)_{e} u_{e}-(\rho v A)_{w} u_{w}}{\Delta x}+\frac{(\rho v A)_{n} v_{n}-(\rho v A)_{s} v_{s}}{\Delta y} \\
=\frac{\left(p_{s}-p_{n}\right)}{\Delta y} \Delta V_{v}+\left\{\left[\frac{\left(\mu \frac{\partial v}{\partial x}\right)_{e}-\left(\mu \frac{\partial v}{\partial x}\right)_{w}}{\Delta x}\right]\right. \\
\left.+\left[\frac{\left(\mu \frac{\partial v}{\partial y}\right)_{n}-\left(\mu \frac{\partial v}{\partial y}\right)_{s}}{\Delta y}\right]\right\} \Delta V_{v}
\end{gathered}
$$

The above equations represent discretized Navier Stokes equation along the $\mathrm{x}$ direction where $\Delta V$ is the volume, $\mathrm{A}$ is the area, $\mathrm{e}$ is the node to the east and $\mathrm{w}$ is the node to the west of $\mathrm{u}$-cell, $\mathrm{n}$ is the node to the north and $\mathrm{s}$ is the node to the south of $\mathrm{v}$-cell ${ }^{17}$.

For laminar flow, the equation of continuity and momentum equations are solved. For turbulent flow, k- $\varepsilon$ model is used to indicate the effects of the turbulence. The $\mathrm{k}-\varepsilon$ model introduces two transport equations for turbulent kinetic energy $\mathrm{k}$ and turbulent kinetic energy dissipation rate $\varepsilon$ in addition to the equation of continuity and momentum equations, given by 


$$
\begin{aligned}
\frac{\partial}{\partial t}(\rho k)+\frac{\partial}{\partial x_{i}}\left(\rho k u_{i}\right)= & \frac{\partial}{\partial x_{j}}\left[\left(\mu+\frac{\mu_{t}}{\sigma_{k}}\right) \frac{\partial k}{\partial x_{j}}\right] \\
& +M_{k}+M_{b}-\rho \varepsilon-Y_{m} \\
\frac{\partial}{\partial t}(\rho \varepsilon)+\frac{\partial}{\partial x_{i}}\left(\rho \varepsilon u_{i}\right)=\frac{\partial}{\partial x_{j}} & {\left[\left(\mu+\frac{\mu_{t}}{\sigma_{\varepsilon}}\right) \frac{\partial \varepsilon}{\partial x_{j}}\right] } \\
+ & C_{\varepsilon 1}\left(\frac{\varepsilon}{k\left(\mathrm{M}_{k}\right)}+C_{\varepsilon 3} M_{b}\right)-C_{\varepsilon 2} \rho \frac{\varepsilon^{2}}{k}
\end{aligned}
$$

where $u_{i}$ is the velocity component along $\mathrm{x}$ direction, $\mu$ is the viscosity, $\mu_{t}$ is the turbulent viscosity, $M_{k}$ is the shear stress-related turbulent kinetic energy production, $M_{b}$ is the buoyancy-related turbulent kinetic energy production, $Y_{m}$ is the compressibility related kinetic energy production. $C_{\varepsilon 1}=1.44 ; C_{\varepsilon 2}=1.92 ; C_{\varepsilon 3}=1.0 ; \sigma_{\mathrm{k}}=1, \sigma_{\varepsilon}=1.3$, and $C_{\mu}=0.09$ are empirical constants ${ }^{18}$.

Discretized equations are iteratively solved by segregated solver using Semi-Implicit Method for Pressure Linked Equations known as SIMPLE algorithm in Fluent software where values $\mathrm{u}_{0}, \mathrm{v}_{0}$, and $\mathrm{p}_{0}$ are initial guess values. The flow equations are solved using guessed pressure field to obtain velocity components $\mathrm{u}_{0}$, and $\mathrm{v}_{0}$. The correction $\mathrm{p}$ ' is defined as the difference between the correct pressure field $\mathrm{p}$ and the guessed pressure field $\mathrm{p}_{0}$. The correction velocity fields are also similarly defined.

$$
\mathrm{p}=\mathrm{p}_{0}+\mathrm{p} ; \mathrm{u}=\mathrm{u}_{0}+\mathrm{u}^{\prime} ; \mathrm{v}=\mathrm{v}_{0}+\mathrm{v}^{\prime}
$$

The discretized continuity equation, on applying the corrected velocity, yields pressure correction equation of the form

$$
\begin{aligned}
& a_{I, J} p_{I, J}^{\prime}= a_{I+1, J} p_{I+1, J}^{\prime}+a_{I-1, J} p_{I-1, J}^{\prime} \\
&+a_{I, J+1} p_{I, J+1}^{\prime}+a_{I, J-1} p_{I, J-1}^{\prime} \\
& a_{I, J} p_{I, J}^{\prime}= a_{I+1, J} p_{I+1, J}^{\prime}+a_{I-1, J} p_{I-1, J}^{\prime} \\
&+a_{I, J+1} p_{I, J+1}^{\prime}+a_{I, J-1} p_{I, J-1}^{\prime} \\
& a_{I-1, J}=(\rho d A)_{I-1, J} ; a_{I+1, J}=(\rho d A)_{I+1, J} ; \\
& a_{I, J-1}=(\rho d A)_{I, J-1} ; a_{I, J+1}=(\rho d A)_{I, J+1}
\end{aligned}
$$

Solving, we get p' which in turn is used to get correct pressure and velocities.

$$
\mathrm{p}_{\mathrm{i}, \mathrm{J}}=\mathrm{p}_{0}+\mathrm{p}
$$

$$
\begin{gathered}
u_{i, j}=u_{0}+d_{i, j}\left(p_{i+1, j}^{\prime}-p_{i-1, j}^{\prime}\right) \\
v_{i, j}=v_{0}+d_{i, j}\left(p_{i, j+1}^{\prime}-p_{j, j-1}^{\prime}\right) \\
d_{i, J}=\frac{A_{i, J}}{a_{i, J}}
\end{gathered}
$$

$\mathrm{p}, \mathrm{u}$, and $\mathrm{v}$ are used to solve all other discretized equations.

The iteration stops if the solution converges. If not, then $\mathrm{p}, \mathrm{u}$, and $\mathrm{v}$ are used as initial guess values in the next iteration and the whole process is repeated till the solution converges.

\subsection{Validation}

Grid validation is done as follows. Different grids have been tried. Perfect mesh combination has been performed to identify the flow pattern by varying the no. of nodes and shape of the mesh. The mass flow rate at the inlet and outlet is $0.6129 \mathrm{~kg} / \mathrm{s}$. Conservation of mass is ensured. Convergence of the solution correct to three decimal places is checked.

\subsection{Error Analysis}

Discretization error(d) and round off error(r) are the errors committed by the computer during each iteration $^{19}$.

$$
\mathrm{d}=\mathrm{A}-\mathrm{S} 1 ; \mathrm{r}=\mathrm{N}-\mathrm{S} 1
$$

' $\mathrm{A}$ ' is the analytical solution of the partial differential equation.'S1' is the exact solution of the difference equation. ' $\mathrm{N}$ ' is the Numerical solution from a computer with finite accuracy. The solution is unstable if the $r_{i}$ 's grow bigger during the progression of the solution from $\mathrm{n}^{\text {th }}$ step to $(\mathrm{n}+1)^{\text {th }}$ step. The solution is stable if

$$
\left|\frac{r_{i}^{n+1}}{r_{i}^{n}}\right| \leq 1
$$

\subsection{Limitation}

If the Space mesh size is reduced, more amount of memory and time computation is required.

\subsection{Future Scope}

This study can be extended to unsteady state with turbulent flow conditions. Single and multiple flows of various 
toxic chemicals can be considered. Many other shapes of sensors and geometry of different indoor environments can be studied for CFD analysis.

\section{Analysis of Results}

In this study, viscous flow of hydrogen-cyanide on the circular sensors has been considered. The flow patterns around the circular sensors placed at different locations are visualized for laminar flow conditions from Figure $2 \mathrm{a}$, Figure $2 b$, Figure $2 c$, Figure $2 d$, and Figure 2e. The turbulent flow pattern around the circular sensors in different models can be viewed from Figure $4 a$, Figure $4 b$, Figure $4 \mathrm{c}$, and Figure $4 \mathrm{~d}$. The velocity around the circular sensors can be visualized with the help of different contours starting from blue to red. Red contour indicate very high velocity and blue contour represent very low velocity.
The velocity values corresponding to different contours are shown in the figures. Red contours are observed on the region perpendicular to the circular sensors which indicates very high velocities ${ }^{8,14}$. This indicates that the contaminants are not captured by the sensors at the region perpendicular to the sensors and the gas cloud keeps moving with high velocity ${ }^{14}$. Blue contours observed at the upstream and downstream sides of the sensors are an indication of low velocity. Stagnation points are identified in the region of low velocity and hence it is an implication of sensing. The contaminants are captured by the sensors at these stagnation points ${ }^{14}$. Comparing the velocity magnitudes of low velocity region in various models, a variation in velocity magnitude is observed round the circular sensors in Model 2, Model 3 and Model 4 as seen in Figure 2b, Figure $2 c$, and Figure $2 \mathrm{~d}$. But the magnitude of velocity around the three sensors in Model 1 remains the same.

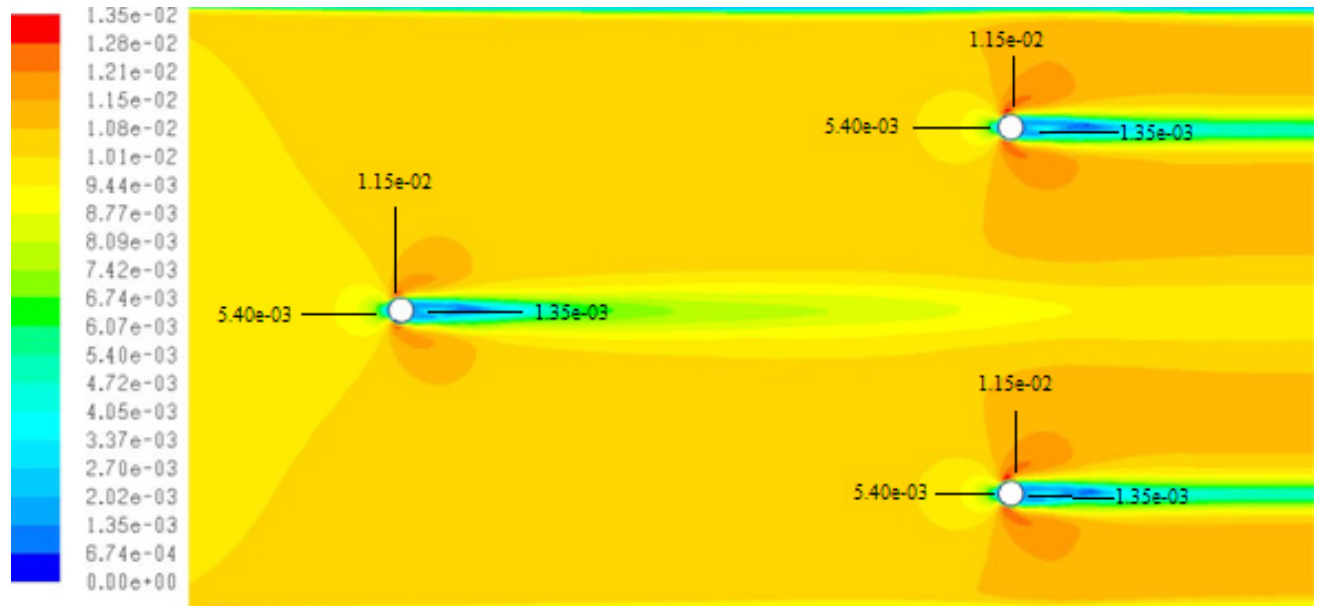

Figure 2a. Laminar flow pattern around circular sensors in Model 1.

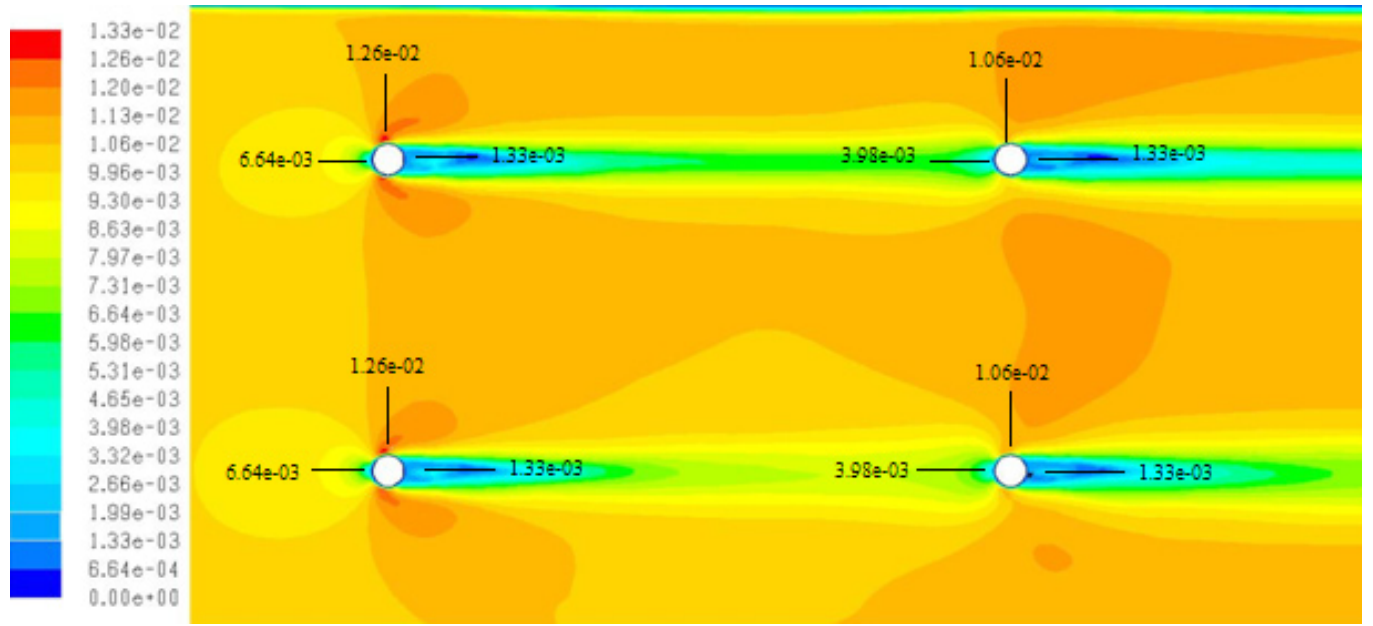

Figure 2b. Laminar flow pattern around circular sensors in Model 2. 


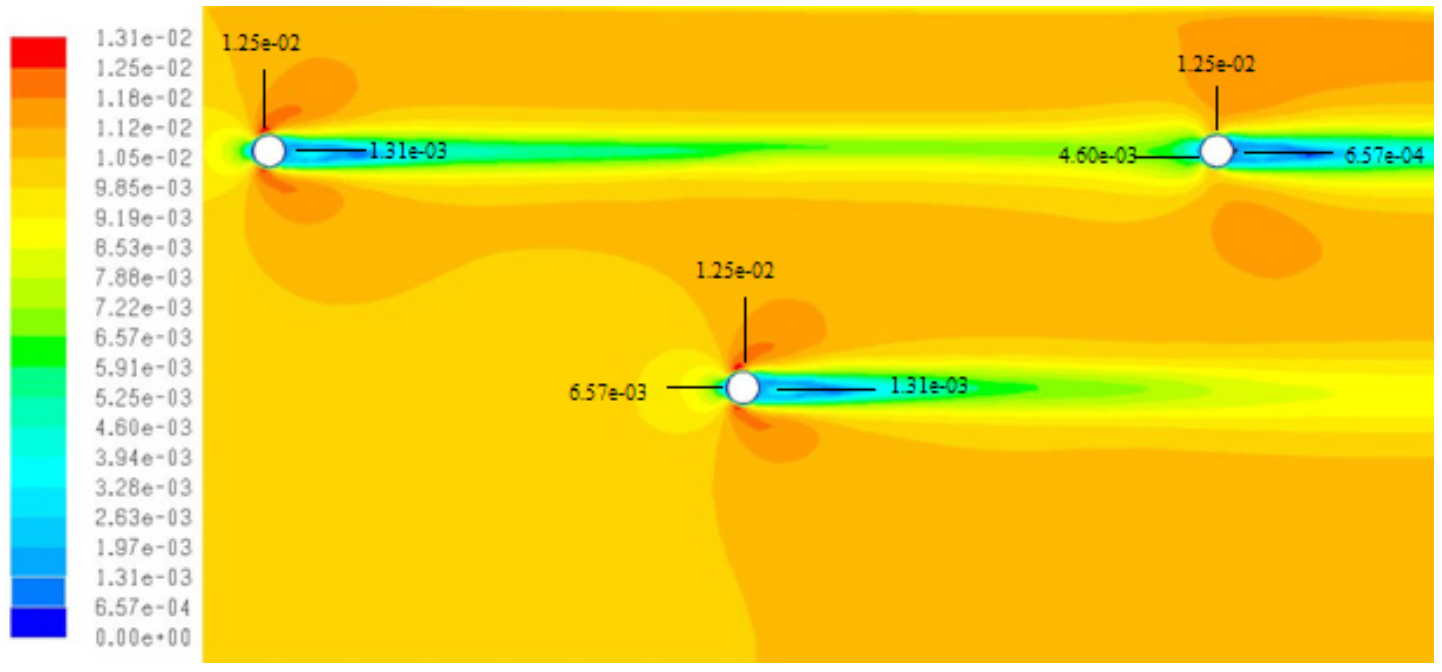

Figure 2c. Laminar flow pattern around circular sensors in Model 3.

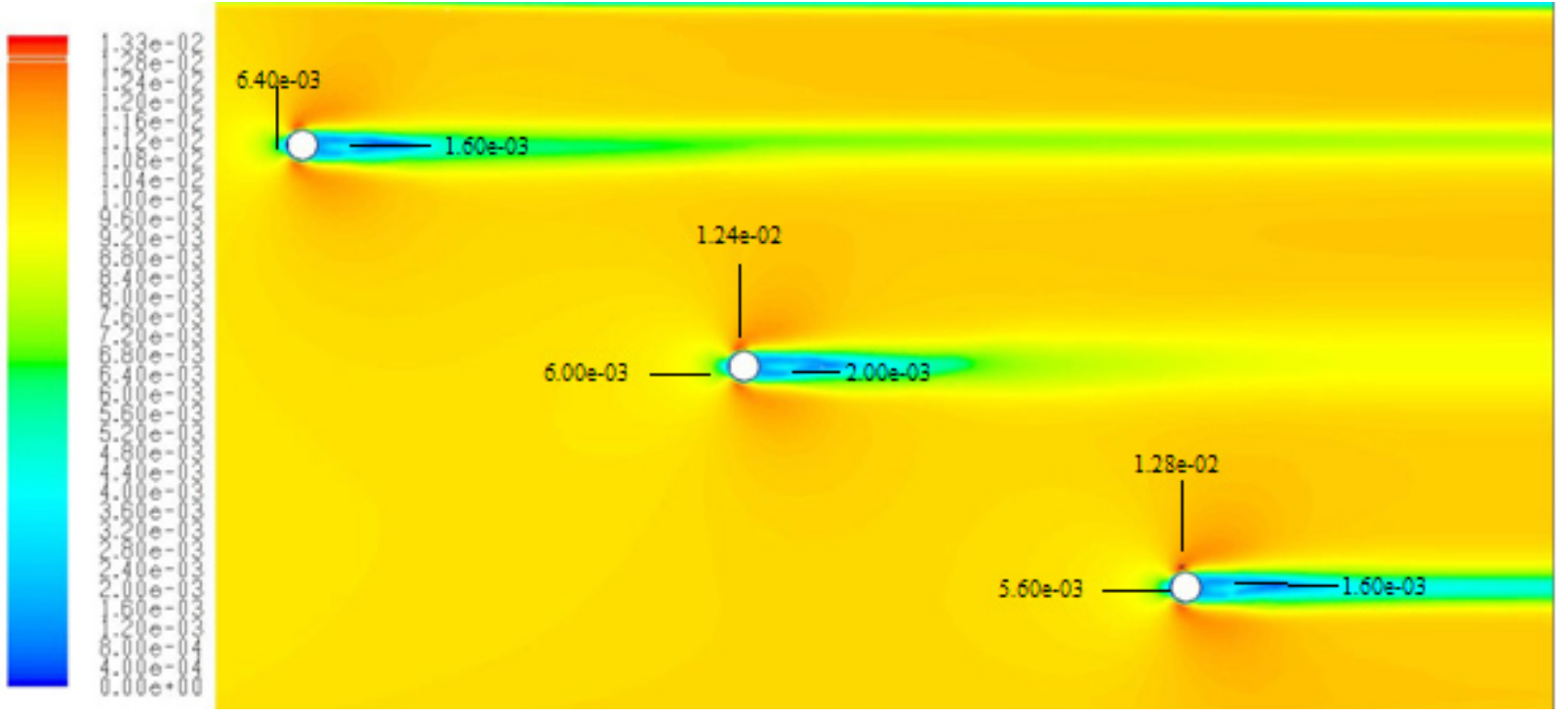

Figure 2d. Laminar flow pattern around circular sensors in Model 4.

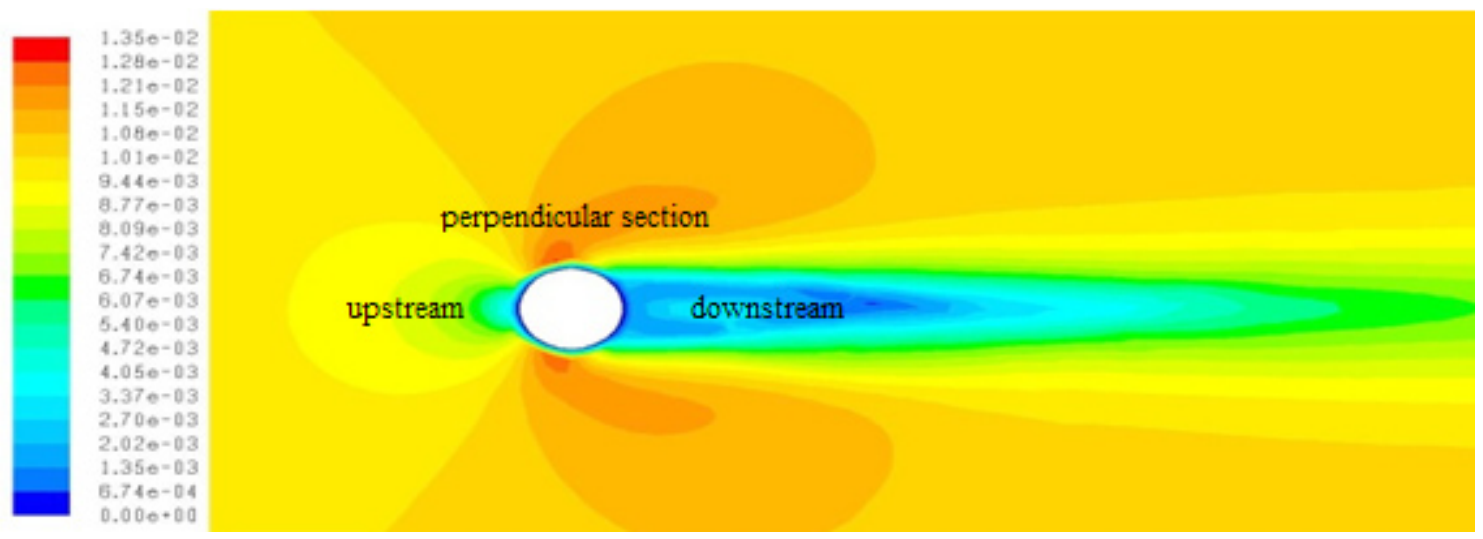

Figure 2e. Contours of Velocity Magnitude for laminar flow in Model 1. 


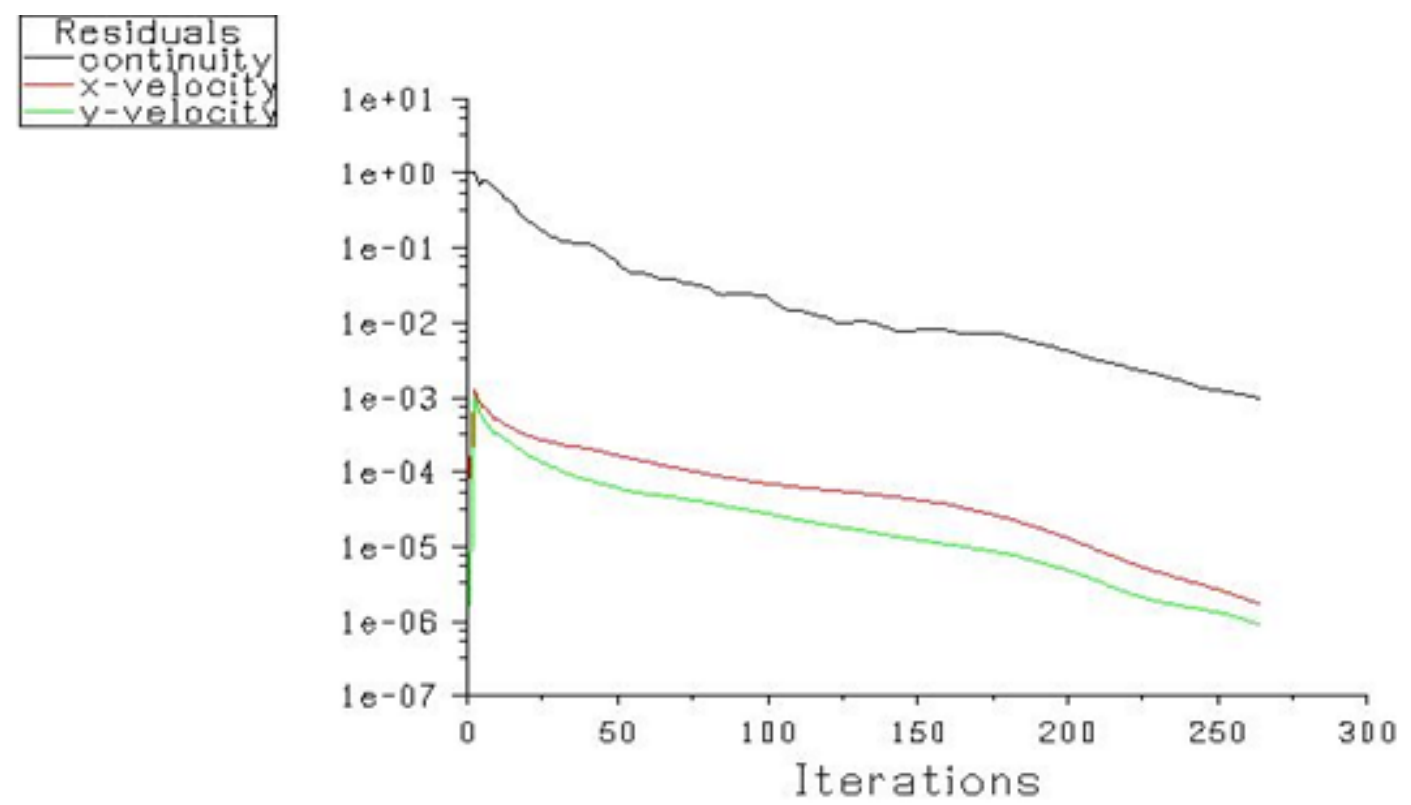

Figure 3a. Velocity iteration plot for laminar flow around circular sensor in Model 1.
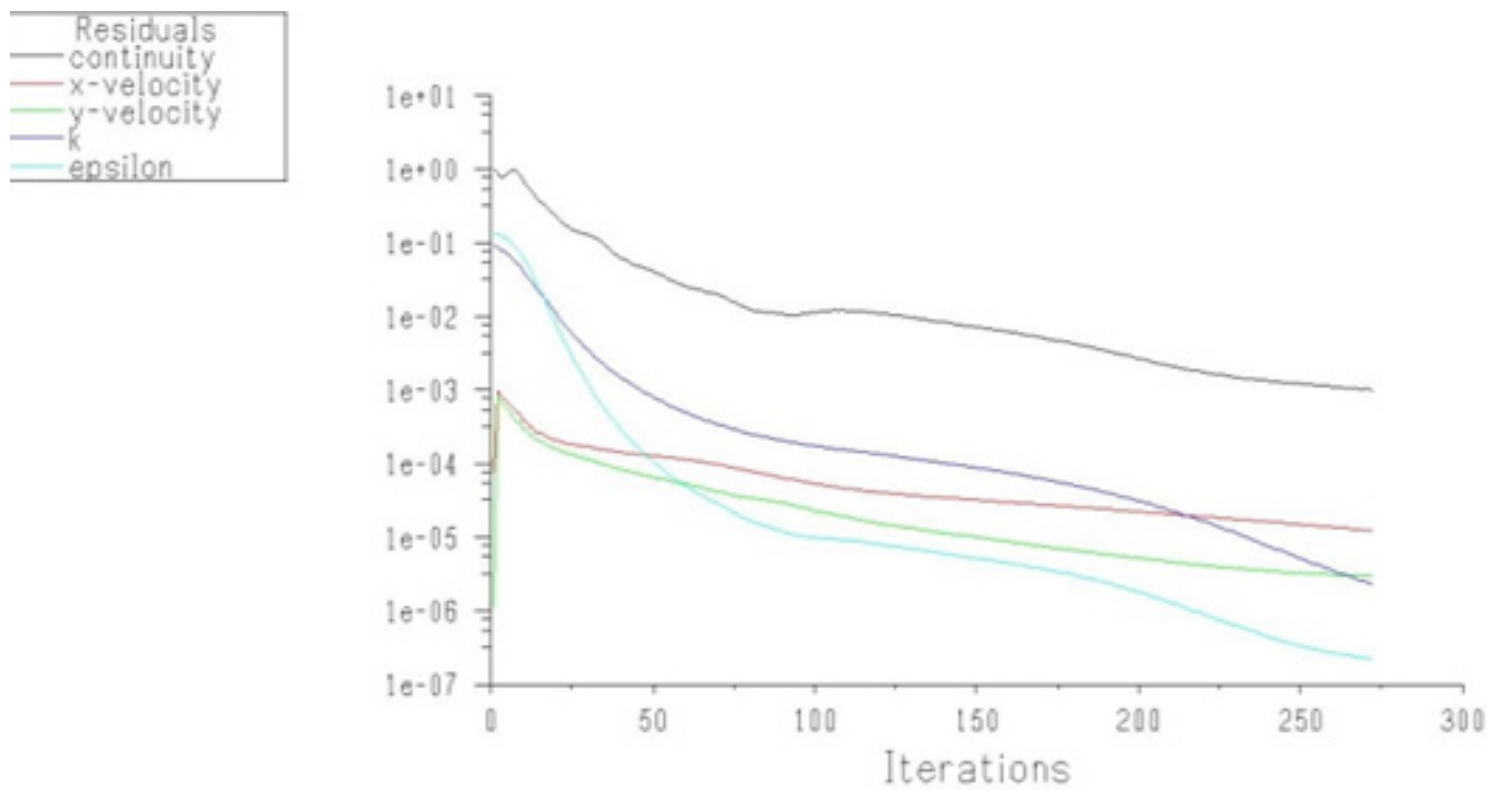

Figure 3b. Velocity iteration plot for turbulent flow around circular sensor in Model 1.

This observation reveals the fact that the flow is disturbed by the placement of sensors in all models except Model 1 .

For Model 1, the velocity magnitude corresponding to the green contour is $6.07 \mathrm{e}-03 \mathrm{~m} / \mathrm{s}$ in the upstream side of the sensor. The velocity magnitude in laminar flow corresponding to the blue contour is $2.02 \mathrm{e}-03 \mathrm{~m} / \mathrm{s}$ in the downstream side of the sensor. The velocity magnitude corresponding to the red contour is $1.21 \mathrm{e}-02 \mathrm{~m} / \mathrm{s}$ in the perpendicular section of the sensor. Similarly for turbulent flow pattern in model1, the velocity magnitude corresponding to the green contour is $2.35 \mathrm{e}-01 \mathrm{~m} / \mathrm{s}$ in the upstream side of the sensor. The velocity magnitude in laminar flow corresponding to the blue contour is $3.36 \mathrm{e}-$ $02 \mathrm{~m} / \mathrm{s}$ in the downstream side of the sensor. But there is a small variation in velocity magnitude corresponding to the red contour as seen in Figure $4 \mathrm{a}$. It is noted that 
in Model1, the velocity magnitude in the perpendicular section of the first sensor is $6.05 \mathrm{e}-01 \mathrm{~m} / \mathrm{s}$ and for the other two sensors the velocity magnitude is $6.39 \mathrm{e}-01$. However the variation is small.

It is important to place the sensors in appropriate locations such that the flow remains undisturbed. Hence the placement of sensors given in Modell is considered as an optimal sensor position for laminar flow pattern. In the case of turbulent flow pattern, in Model 1 variation is small when compared to other models.

Pressure distribution at different points on and around the circular sensors is presented in Figure 6a, Figure 6b, Figure $6 \mathrm{c}$ and Figure $6 \mathrm{~d}$. High pressure region is an implication of sensing. The high pressure value in Model 1 for laminar flow is found as $4.49 \mathrm{e}-05$ pascals and the low pressure is noted as -5.37 pascals. The pressure values remain the same for all sensors in Model 1 and variations are observed in pressure values for all other models.

Streamline pattern given in Figure 5 gives the direction of flow of fluid particles. Small length of the vector indicates low velocity. Convergences of the solution correct to 3 decimal places are ensured as given in Figure 3a and Figure $3 \mathrm{~b}$. The solution converges at 264th iteration for Model 1, 301st iteration for Model 2, 741st iteration for Model 3, and 265th iteration for Model 4 for laminar flow and the solution converges at 272nd iteration for Model 1, 266th iteration for Model 2, 331st iteration for Model 3, and 236th iteration for Model 4 for turbulent flow conditions. The wall shear stress for laminar flow around circular sensors is calculated as seen in Figure 7.

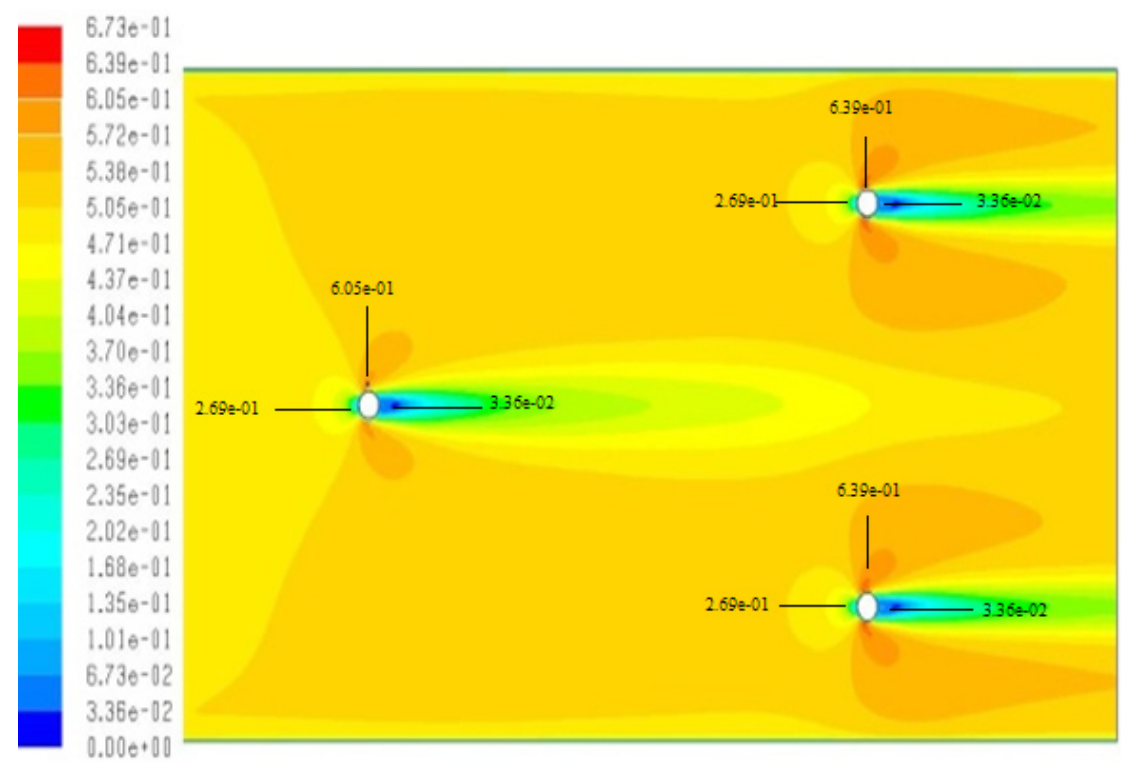

Figure 4a. Turbulent flow pattern around circular sensors in Model 1.

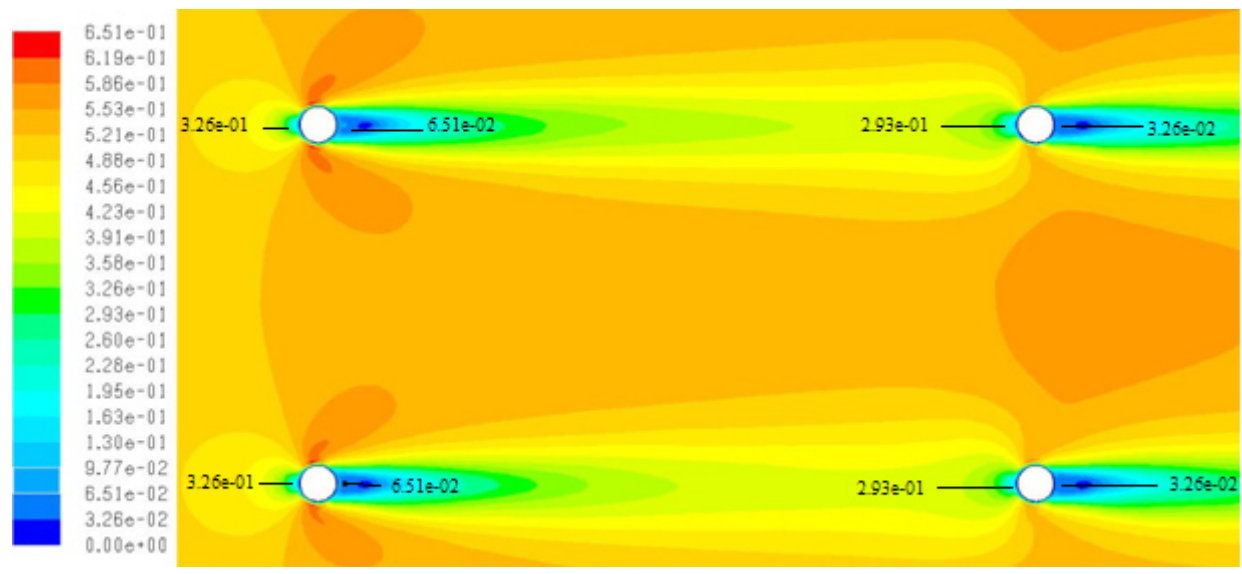

Figure 4b. Turbulent flow pattern around circular sensors in Model 2. 


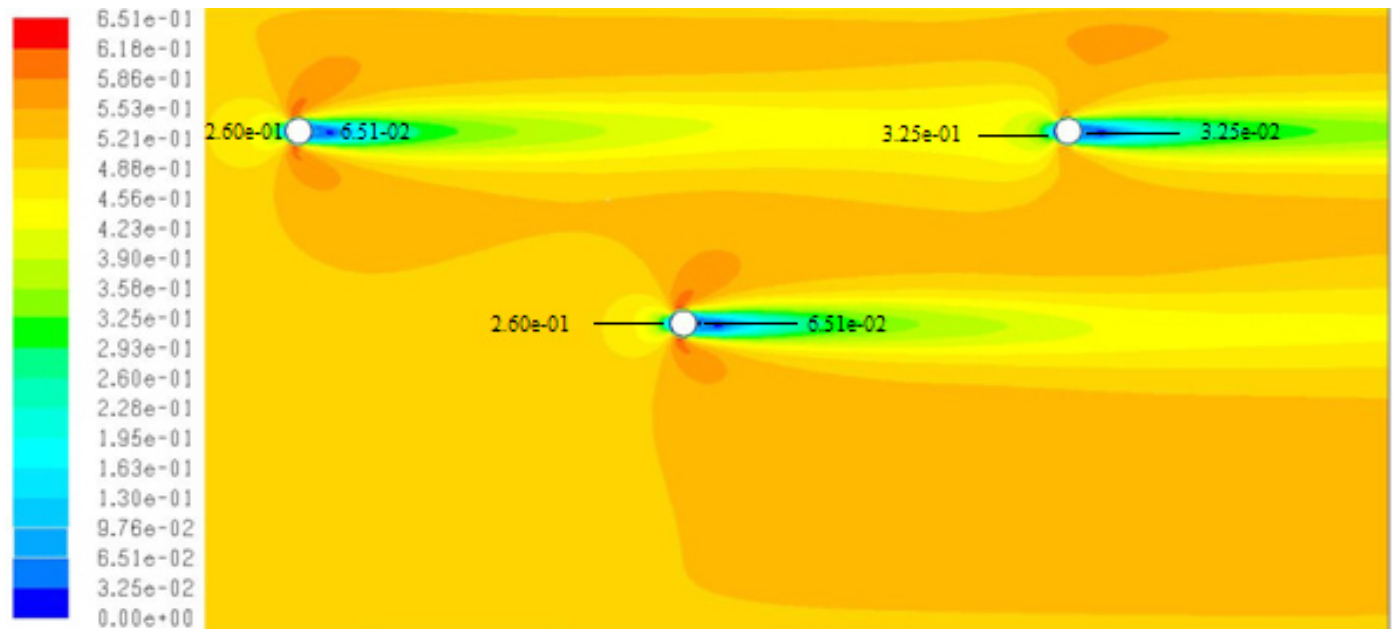

Figure 4c. Turbulent flow pattern around circular sensors in Model 3.

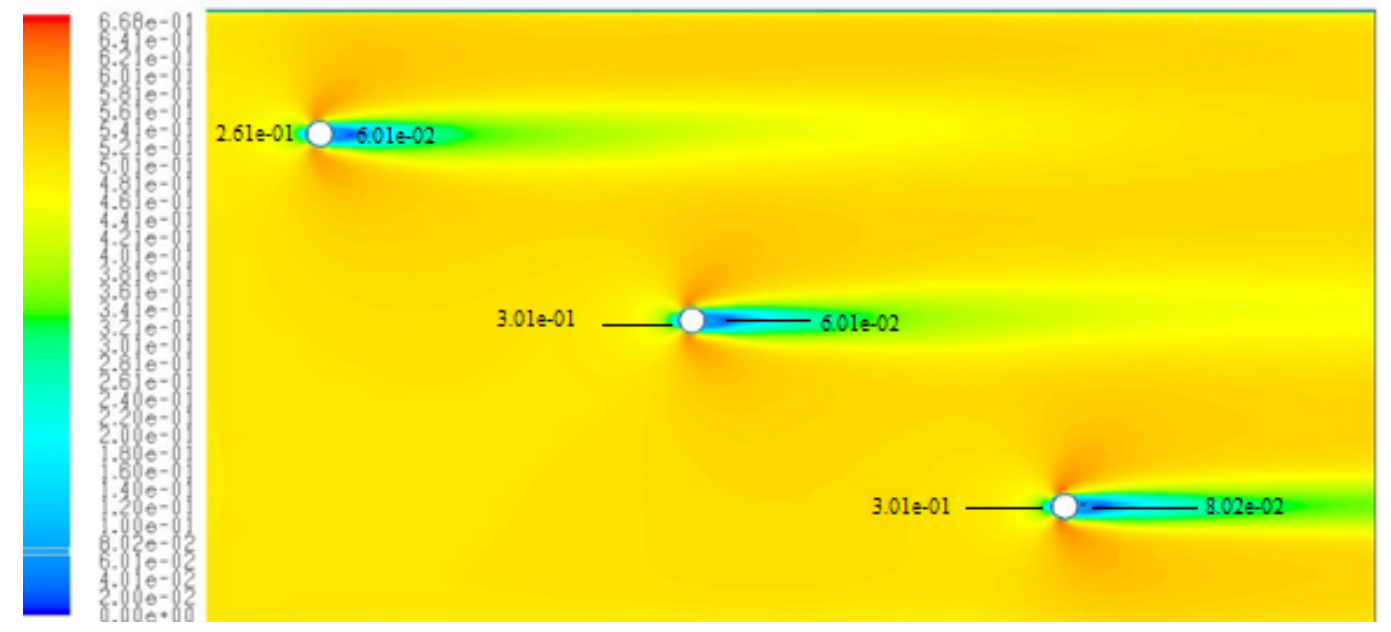

Figure 4d. Turbulent flow pattern around circular sensors in Model 4.

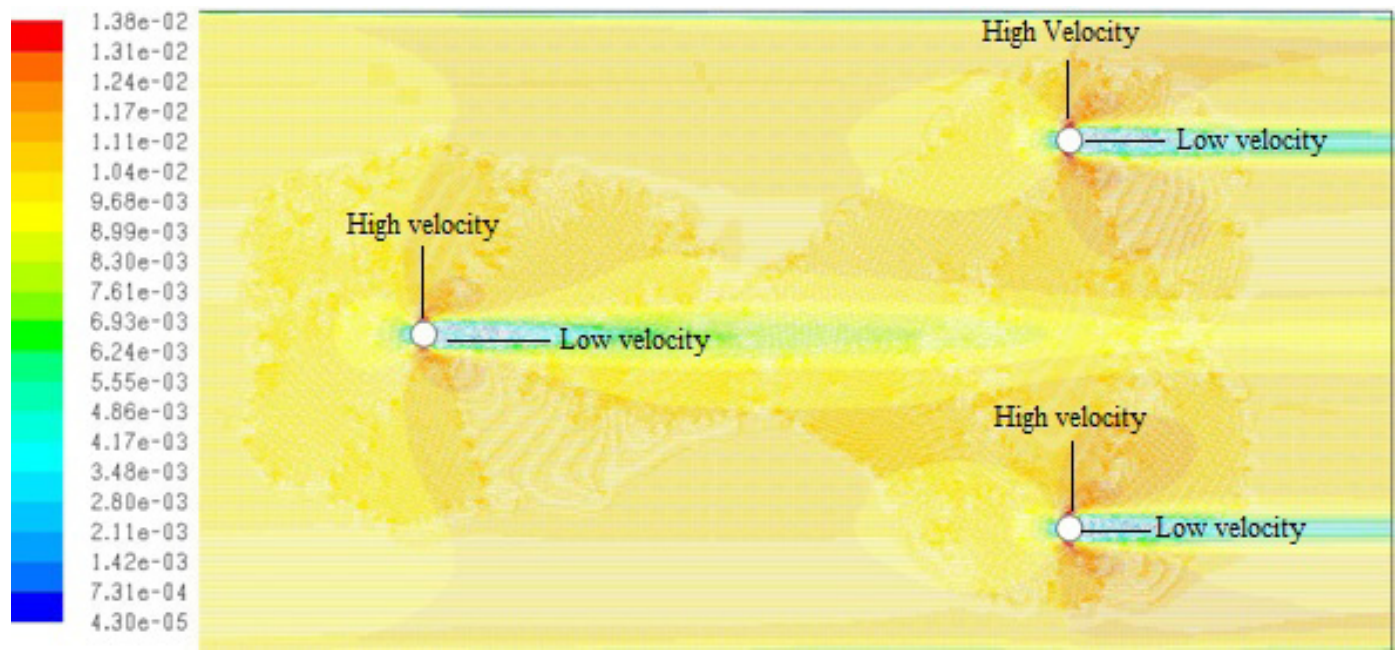

Figure 5. Streamline pattern for laminar flow around circular sensor in Model 1. 


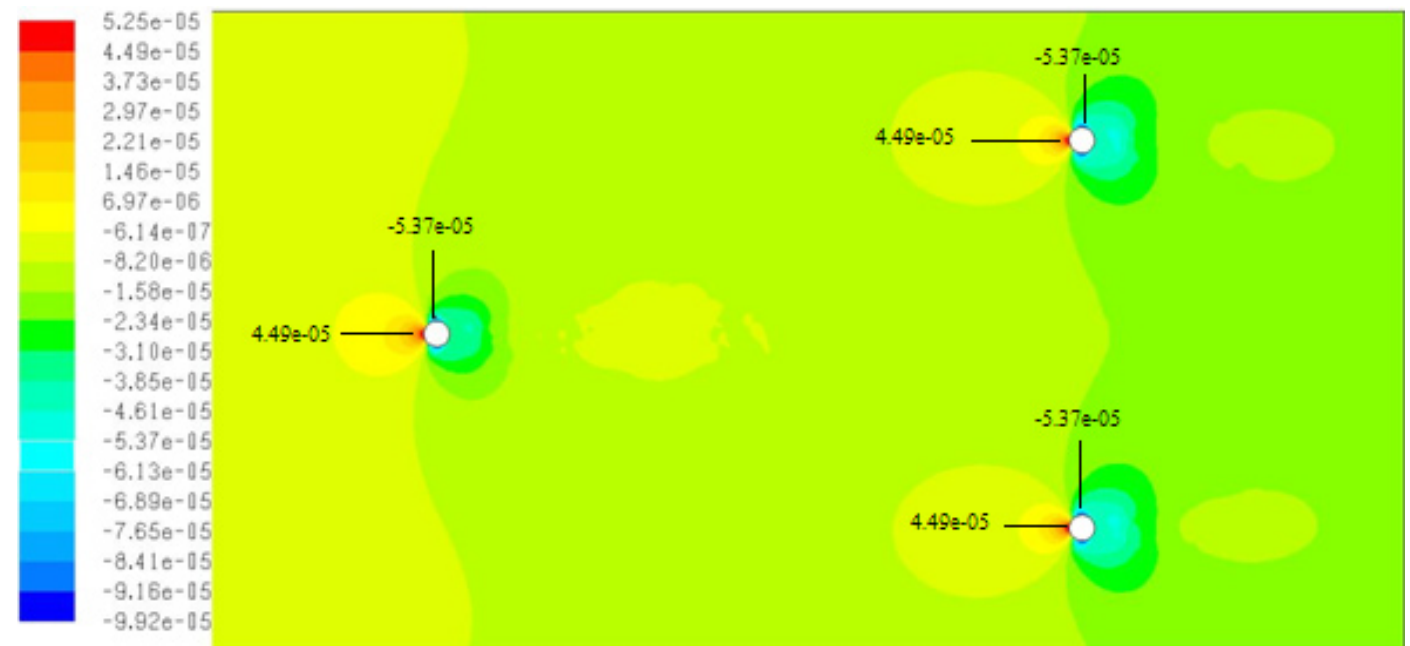

Figure 6a. Pressure distribution for laminar flow around circular sensors in Model 1.

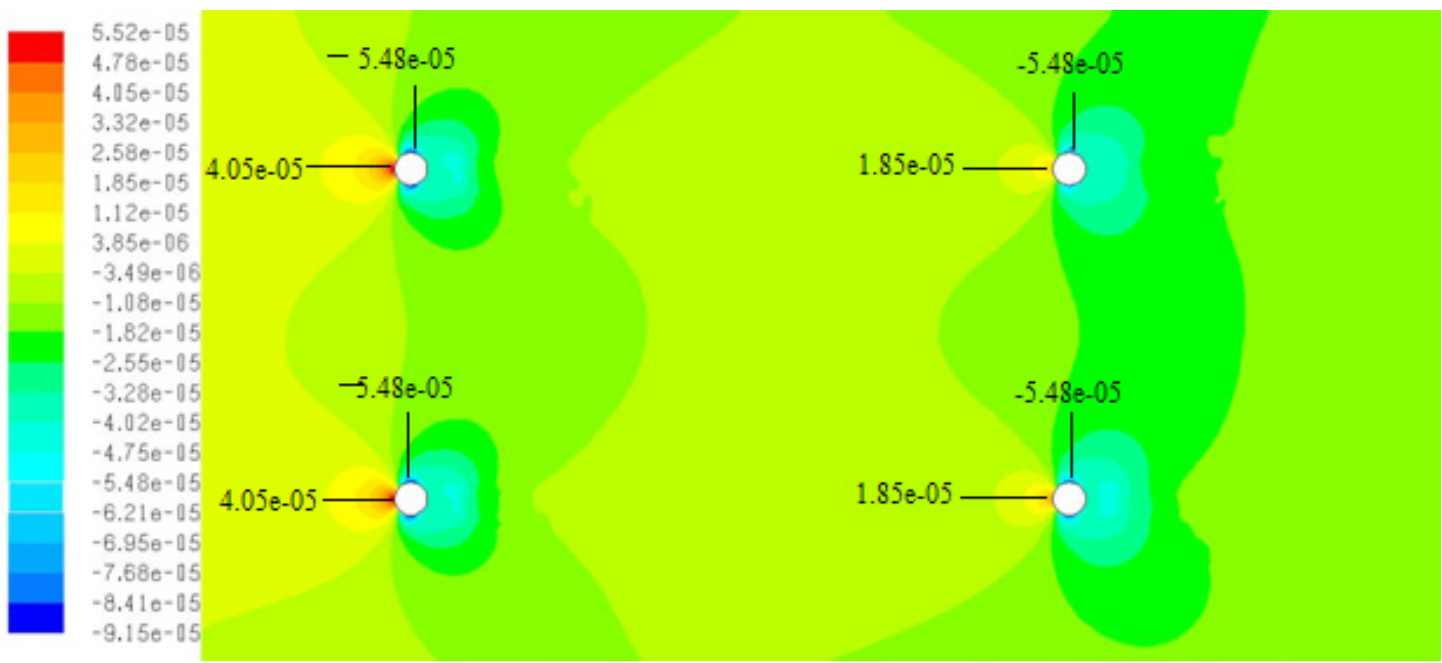

Figure 6b. Pressure distribution for laminar flow around circular sensors in Model 2.

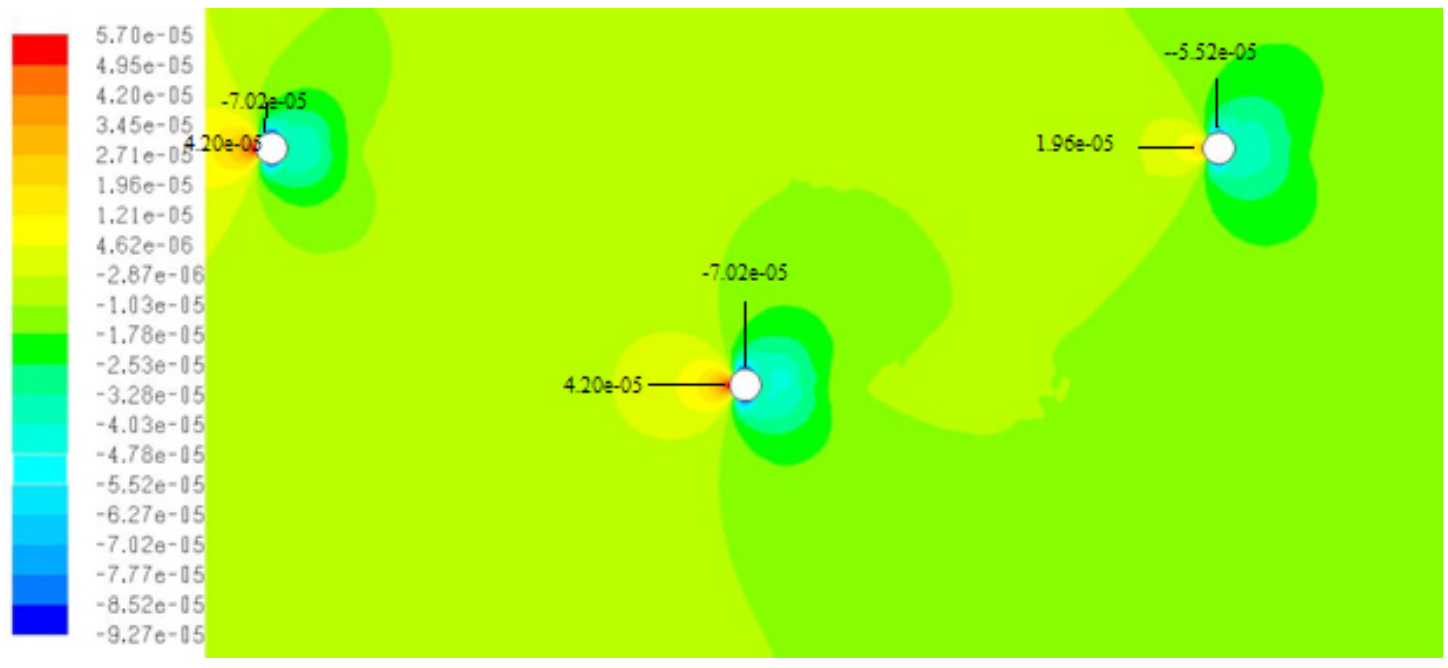

Figure 6c. Pressure distribution for laminar flow around circular sensors in Model 3. 


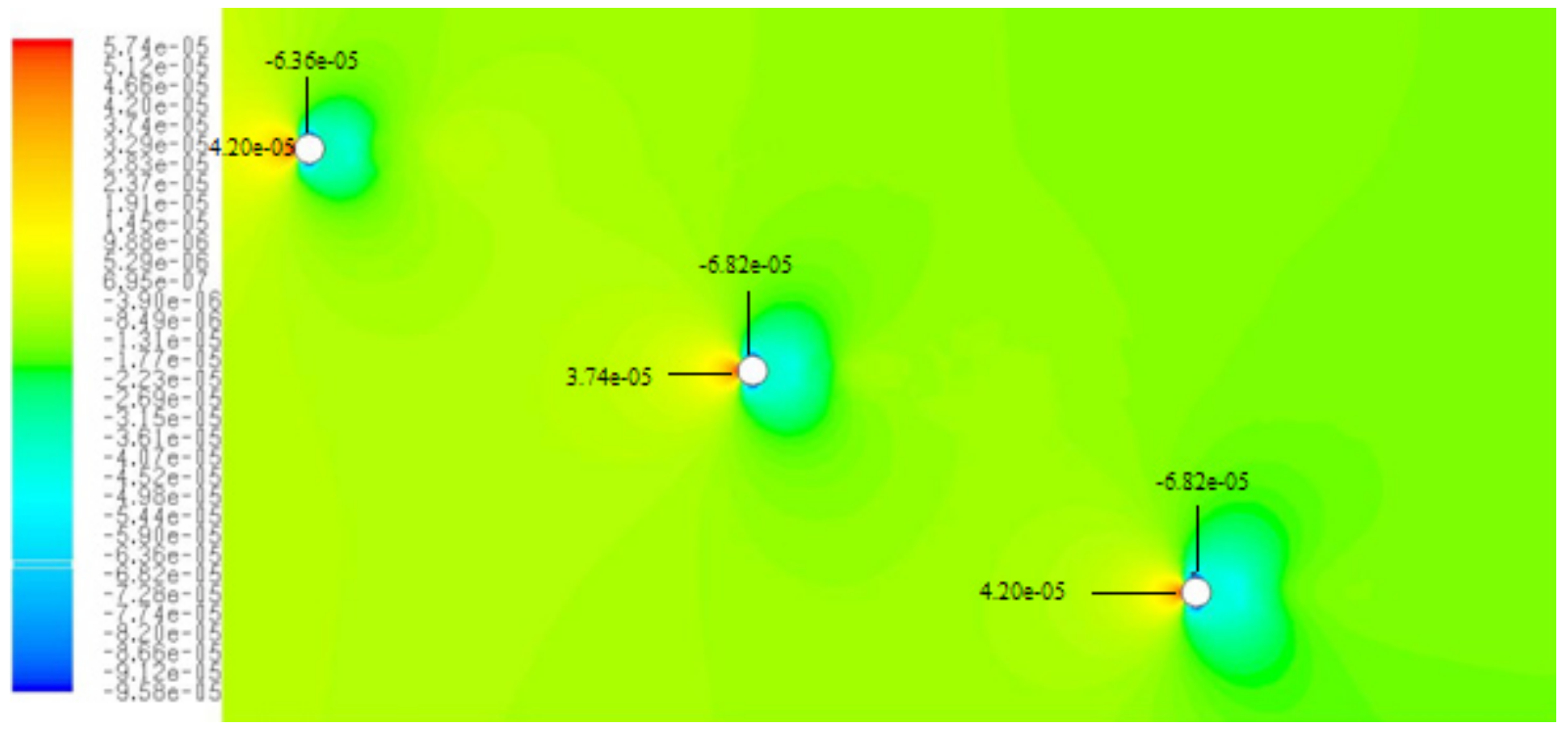

Figure 6d. Pressure distribution for laminar flow around circular sensors in Model 4.

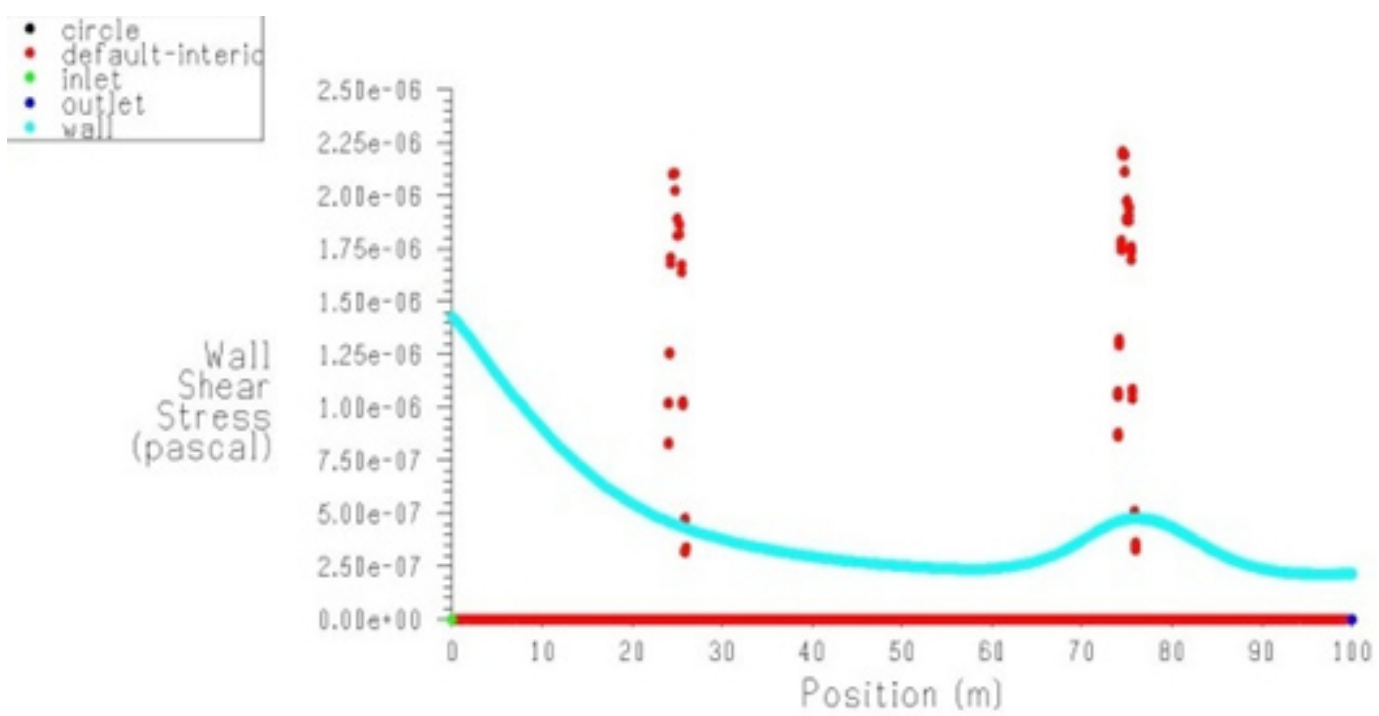

Figure 7. Wall Shear Stress plot for laminar flow around circular sensors in Model 1.

\section{Conclusion}

A two dimensional, viscous, incompressible flow field around circular sensors has been analyzed with laminar and turbulent flow pattern under steady state conditions. The flow pattern of hydrogen-cyanide around the circular sensors is studied to determine the optimal sensor placement. For Model 1, the velocity magnitude corresponding to the green contour is $6.07 \mathrm{e}-03 \mathrm{~m} / \mathrm{s}$ in the upstream side of the sensor, blue contour is $2.02 \mathrm{e}-03 \mathrm{~m} / \mathrm{s}$ in the downstream side of the sensor and red contour is $1.21 \mathrm{e}-02 \mathrm{~m} / \mathrm{s}$ in the perpendicular section of the sensor. These values obtained as a result of CFD simulation remains unique for all the three sensors used in the Model 1. But these values keep changing for the circular sensors used in the other models. Hence the placement of circular sensors in Model 1 is fixed as optimal sensor placement. It is because the flow is not disturbed due to the arrangement of sensors in Model 1. Hence it increases the efficiency of sensing and thereby gives an early warning about the toxic gases 
before it reaches the occupants. This information has been obtained based on the velocity, pressure and streamline pattern of hydrogen-cyanide. Hence the results of this study can be considered in fixing the optimal sensor position to sense effectively and get early warning about the toxic gases.

\section{References}

1. Organisation for the Prohibition of Chemical Weapons. Retrieved 2009-01-14. Hydrogen Cyanide.

2. Available from: http://www.sierramonitor.com/gas/about/ Gas-Detection/Hydrogen-Cyanide-HCN-gas-detection.php.

3. Available from: www.mil-ram.com/public/ta_2102_hcn_ page.html

4. Available from: www.grainger.com/category/ecatalog/N-1z0dep 1

5. Arvelo J, Brandt A, Roger RP, Saksena A. An enhancement multizone model and its application to optimum placement of CBW sensors. ASHRAE Transactions 2002; 108(2):818-25.

6. Liu Z. Odour source Localization using multiple plume tracing mobile robots. [Ph.D. Thesis] University of Adelaide: Australia; 2000. p. 1-33.

7. Awadallai MS, Tien-Fu L, Tiani ZF, Dalli BP. CFD Modeling of 3D Indoor Gas Contaminant Plumes for Testing Search Algorithms of Mobile Robot. Ninth International Conference on CFD in the Minerals and Process Industries; 2012; CSIRO, Melbourne, Australia. p. 1-7.

8. Ishida $H$, Tsuruno M, Yoshikawa K, Moriizumi T. Spherical gas sensor array for three dimensional plume tracking. 11th International Conference on Advanced Robotics Coimbra; Portugal. p. 369-74.

9. Zhai Z, Srebric J, Chen Q. Application of CFD to predict and control chemical and biological agent dispersion in buildings. International Journal of Ventilation. 2003; 2(3):251-64.
10. Obenschain K, Boris J, Patnaik G. Using CT-ANALYSTTM to optimize sensor placement. Proceedings of SPIE Orlando, Florida. 2004; 5416:14-20.

11. Löhner R, Camelli F. Optimal placement of sensors for contaminant detection based on detailed 3D CFD simulations. Engineering Computations. 2005; 22(3):260-73.

12. Zhang $\mathrm{T}$, Chen Q. Novel air distribution systems for commercial aircraft cabins. Building and Environment. 2007; 42(4):1675-84.

13. Liu Z, Lu. Odor source localization in complicated indoor environments. 10th Int Conf on Control, Automation, Robotics and Vision; 2008; Univ. of Adelaide, Adelaide, South Australia. p. 371-7.

14. Shyla MV, Naidu KB, Kumar VG. Optimization of sensor position on Different surfaces using CFD Analysis for reducing accidents caused by emission of toxic gas in Industries. International conference on Advance Computing-2013, ICOAC-13; 2013; Anna University, Chennai, India. p. 1-8.

15. Guerrero J. Numerical Simulation of the unsteady Aerodynamics of flapping flight. [Ph.D. Thesis] 2012; chapter 3:34-51.

16. Shyla MV, Naidu KB. A Computational Fluid Dynamic Model of Human Sniffing. International Journal of Mathematical Science and Engineering. 2013; 7(1):1243-7. ISBN 0976-5166

17. Versteeg H, Malalasekra W. An introduction to Computational Fluid Dynamics The Finite Volume Method. 2nd ed. South Asia: Pearson Education Ltd; 2011. ISBN 978-81-317-2048-6. p. 193-225(in English).

18. Pontiggia M, Derudi M, Busini V, Rota R. Hazardous gas dispersion: A CFD model accounting for atmospheric stability classes. Journal of Hazardous Materials. 2009; 171(1-3):739-47.

19. Wendt JF, Anderson JDJr, Degroote J, Degrez G, Dick E, Grundmann R, Vierendeels J. Computational Fluid Dynamics an Introduction. 3rd ed. Berlin, Heidelberg: Springer-Verlag; 2009. ISBN: 978-3-540-85055-7. p. 97-103(in English). 